\title{
Form Deconstruction of Chinese Contemporary Landscape Architecture-Take the Design of Wuhan University of Technology Innovation and Entrepreneurship Park as an Example
}

\author{
Zhe Zou ${ }^{1}$, Ting Gan ${ }^{2 *}$, Xiduo $\mathrm{Yi}^{3}$ \\ ${ }^{1}$ College of Art and Design, Jimei University Landscape Committee of Fujian Sculpture Association Xiamen, China \\ ${ }^{2}$ College of Art and Design, Wuhan University of Technology, Wuhan, China \\ ${ }^{3}$ College of Foreign Languages, Fujian Normal University College of Foreign Languages, Jimei University, Xiamen, China
}

\begin{abstract}
There are several differences in architectural forms and cultural systems between the east and the west, which are attributed to different traditional philosophical ontologies. China takes "Tao" as its ideological basis emphasizes: "Nothing". Chinese fundamental principles are deeply related to philosophy and metaphysics. Traditional culture pursues spiritual connotations. Inversely, the west regards "Logos" as the origin of the world. This emphasizes the "being", with fundamental principles based in geometry, mathematics and science. The west has established a scientific spatial consciousness since the beginning of the Renaissance. It is based on mathematical relations and geometric principles, and focused on the pursuit of matter. "Logos" is an important aspect of Western philosophy, meaning that the "center", the "source" or the "truth", is a transcendental "presence." Pythagorean's mathematical theory and Plato's "rational" thinking are ultimately a variant of "Logos". The external imitation of nature in western classical gardens aims to explore the essence of nature. The separation of subject and object as the fundamental formula of Western philosophical epistemology has made mankind dominating nature for a long time. It leads to the deterioration of our living environment. Deconstructive philosophical thought is the subversion and criticism of the "Logos centralism" since ancient Greece. It eliminates the sense of "center" and the "subject-object dichotomy", which is the process of transforming "being" to "nothing". "Anthropocentrism" is disintegrated, when people and nature re-entered in an equal dialogue and symbiosis. Therefore, the symbiotic relationship between man and nature has been reshaped by the spirit of deconstruction. This is highly compatible with the ideological concept of "harmony between man and nature". The cultural spirit of harmony is precious in Chinese traditional philosophy.

Taking the design project of the Innovation Pioneer Park of Wuhan University of Technology as a casestudy, this paper analyses the morphological deconstruction characteristics and their cultural connotation to contemporary Chinese courtyard spaces. It explores a design language and method that breaks through the traditional thinking paradigm, bridging it to characteristics of a particular era as well as the aesthetic appeal. This is not a universal design paradigm, but an exploratory series of philosophical speculative processes, which in turn can inform a dynamic and sustainable development. It shows ideological essence of reminiscent of culture and spirit of the traditional Chinese landscape. Contemporary people's world views should be manifest. By doing so, it becomes a conceptual, radiant and pioneering Chinese cultural spiritual symbol in a chaotic contemporary society.
\end{abstract}

\section{INTRODUCTION}

Throughout history, design has been understood as the product of social evolution. Prior to the industrial revolution, the western world explored primarily the construct of beauty through a rationalistic doctrine, most of which was used for natural simulation and material reproduction, contributing to an architecture and landscape presenting a strong axis of "symmetry". In turn, the eastern world had a more respectful attitude towards intuitive perception, with strong emphasis on the relationship between nature and human emotions, often called the "pursuit of harmony between man and nature". After the industrial revolution, and under the dual influence of technical rationality and humanistic spirit, western landscape design has been gradually transformed to find a mediated "equilibrium".

Although China completed its industrial revolution later than the western world, its design pattern and process has presented us with similar characteristics. When the post-industrial revolution and the technological era arrived, ecological and sustainable development became the core issue for all mankind. Diversity, openness,

\footnotetext{
*Corresponding author: gantt2011@163.com
} 
rheology and self-organization have now become the mainstream of landscape design in the social context of the western world in order to dissipate the subject and deconstruct the mass culture of self-spirits. In the context of globalization, informatization, and openness of the "big data era", China has been greatly influenced by the western culture and its design has also appeared in the synchronic shape of deconstruction to a different degree.

The transformation of western ideology from logical to structure and post-structure not only embodies the inner logic of the concept of landscape creation and the development of formal techniques, but also reflects the western social life conditions and the aesthetic demands of different periods. In the 1960s, the deconstruction of Western philosophical schools represented by Jacques Derrida, strongly criticized and subverted the "logocentrism", which the western world had regarded as paramount since the age of classicism. Later, this "binary opposition" evolved into modernism, and began to reveal something complex, chaotic and pluralistic as a reflection of postmodern society. Subsequently, Peter Eisenman and other architects with a keen sense of innovation responded to the great changes of the times, overthrowing the traditional architecture discourse system and deconstructing the philosophy into an architectural language of research, which created many non-central, split, incomplete, dislocated, and unstable architectural forms, setting off a worldwide design concept, content, aesthetics, significance and value of re-definition. "Selfsufficient architecture" of Peter Eisenman (Jacques, 1993), "structural aesthetics" of Frank Gehry (Thomas, 1995), "city fantasy" of Rem Koolhaas (Rem, 1995), "concept and mark" of Bernard Tschumi (Charles, 2007), and the "fluid buildings" of Zaha Hadid, revealed future design trends in a new era. From the dual opposition of "man and nature" to the contemporary aesthetics of "de-centered" and "anti-dualism", the west has become more inclined towards the traditional Oriental aesthetics of "advocating nature as beauty".

As the most classical architectural element in China, the courtyard has been greatly influenced by Western deconstructionism. Compared with other elements, the courtyard has more recessive, elegant and scholarly features, with a superiority of blending with landscapes. In the traditional Chinese architectural system, the courtyard is usually inside the house. It functions as the pivot of "Yin- Yang" following the circulation of nature. The quadrangle is the basic unit of a Chinese house system, most of which have the characteristics of axial symmetry and inward closure. The thoughts of four cardinal points and axis incorporate with geometrical layout. Reservation is the keyword, which blended into the imagery of traditional gardens naturally. In the contemporary context, the regular pattern of quadrangle has been broken. Instead, many fractal, fragmented, incomplete, dislocated and unstable courtyard spatial morphologies have emerged. This morphological "deconstruction" is part of deep structural adaptions to the development of a complex society and the manifestation of contemporary human spirit. As a critical, innovative, advanced design concept and method, "deconstruction" will continuously interact and conflict with "structure".
Within this process, a pluralistic landscape world may be created, where man and nature can coexist harmoniously.

\section{BACKGROUND}

Chinese traditional culture is based on the philosophical thoughts of Confucianism, Taoism and Buddhism and explores the spiritual transcendence of human beings in the process of returning to nature. Represented by Lao and Zhuangzi, Taoist regards Tao as the origin of universe prior to natural existence, and advocates a natural world outlook and methodology. Everything derives from Tao and follows the laws of cosmic movement.

"The way that can be told of is not an Unvarying Way;

The names that can be named are not unvarying names. It was from the Nameless that Heaven and Earth sprang;

The named is but the mother that rears the ten thousand creatures, each after its kind." (Lao Tzu, 1998, p. 2)

Although Taoism regards "Tao" as the origin of the creation of all things in the universe, it refers to "nothing". Tao has the ontological characteristics of Chinese traditional philosophy and is the starting point of exploring the origin of the universe in Chinese traditional culture. "Heaven and earth are born with me, and all things are one with me", which clarifies a homology between man and nature, both of which are essentially synesthetic.

"There was a spontaneous process going on before the natural world took form,

Still and silent, an unaltered process,

Going tirelessly through unending cycles; just like a mother to our world. I don't know its name so I simply call it ... the way. Forcing a name on it, I call it ... the greatest. Great means it goes forth,

Going forth means it reaches afar,

And reaching afar means it returns. Yes: the way is great,

The heavens are great,

And the earth is great;

We humans emulate the earth,

The earth emulates the heavens,

The heaven in turn emulate the way, And the way emulates what just happens, spontaneously." (John, 2007, p. 25)

Everything is in the movement of space-time. Without the movement of matter, space-time does not exist. The movement of matter forms the combination of different substances and then produces chemical reactions. Life can be generated and also thought. Taoist holds that beauty lies in truth as well as in nature. It advocates nature and pursues a pristine spiritual realm in order to seek spiritual freedom. Confucianism, led by Confucius, takes "harmony between man and nature" as its main context, pursuing the wellbeing and harmony between man and nature. In Confucius' view, the social values of human beings are the result of perception of nature with sentimental and poetic feelings that are to be consistent with nature. The idea of "the wise love mountains, the benevolent love water" is the aesthetic embodiment of "harmony between man and nature". Influenced by 
Confucianism and Taoism, foreign Buddhism also borrowed the concept of "Tao". Confucianism, Taoism and Buddhism all regard "Tao" as the ultimate existence of all things in the universe, which is the logical starting point of Chinese traditional civilization. Tao is the core category of ancient Chinese philosophy, containing a dialectical logic in a relationship of unity of opposites, between subject and object, noumenon and phenomenon. It acknowledges the simple design philosophy of harmonious coexistence of universe, nature and human beings.

\section{Proposed Method}

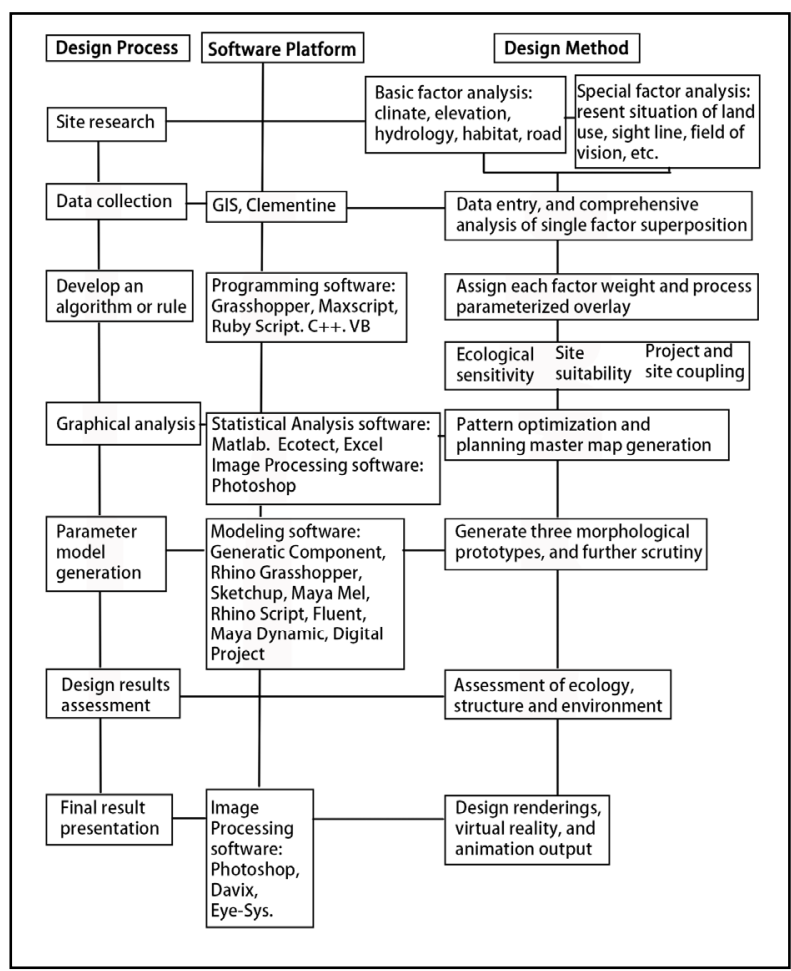

Figure 1. Design process, technology and methods of "from bottom up"

Interpreting the concept of "chaos as nonlinearity", the form of courtyard space could be designed based on a "bottom-up" approach. Designers can take advantage of computer-aided design for thinking, analysing and expressing. The design process would include field data collection and sorting, graphic analysis, algorithm or rules, emerging generation of ideas, results from assessment, and so on. Therefore, the harmonious coexistence in the relationship between people, nature, and society can be reshaped during the rheological, uncertain, dynamic selforganization process of interaction.

\section{Case study}

This paper focuses on the design project of the Innovation Pioneer Park of Wuhan University of Technology for college students. The project is located beside Nanhu Lake in Hongshan District of Wuhan City in China, adjacent to Dingziqiao South Road in the west, Airport Road in the south and Xiongchu Avenue in the north. The planned area is about 130 hectares totally. The building of Innovation Pioneer Centre of college students is nearly 34 meters high. And the construction area is about 38,700 square meters totally. The building's function is very complex, which is the most abundant and innovative building in the entire campus. The Innovation Pioneer Centre not only shows the new image of college students' innovation and entrepreneurship, but also marks the new development trend of China's higher education system. It aimed at creating a unique, functional, advanced innovation and entrepreneurship park for college students.

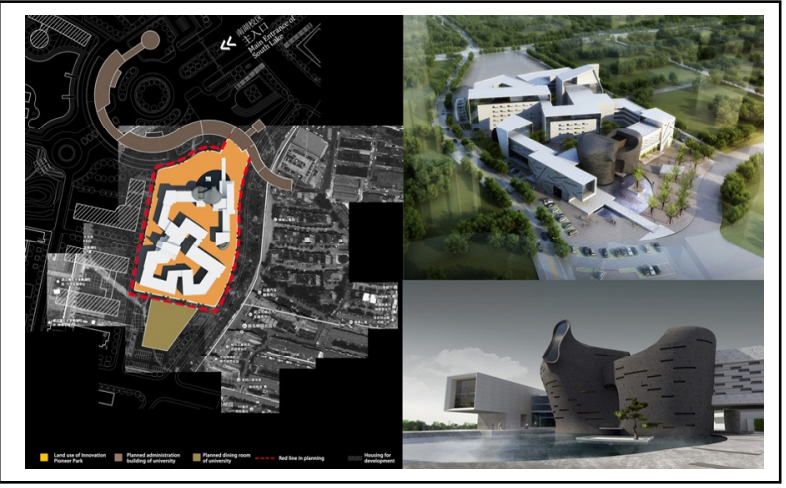

Figure 2. Plan of Innovation Pioneer Park of Wuhan University of Technology (upper left)

Figure 3. Aerial view and Architecture morphology (upper right)

\subsection{Ecological Priority}

The case-study boundaries are confined within 238 meters long from south to north and nearly 130 meters wide from east to west. Wuhan's climate is "cold in winter and hot in summer". The first consideration in this case is to avoid extreme climate conditions and form an effective "micro climate". To control the northwest wind in winter, the northwest front of the building has been enclosed while the southeast front stayed opened, maximising ventilation through the buildings, drawing in the dominant wind in the summer and sunshine in the winter. The planting of wind shelterbelts also provides a cooling effect, creating a microclimate on the site (Figure 4). The underground space is formed by the floor slab, 1.5 meters higher than the outdoor floor, assisting with good lighting and ventilation to minimize energy consumption and carbon emission. The key point of the design is the rainwater garden, creating a water body through the use of rainwater. Also, water for irrigation is considered in the design.

\subsection{Creative Image Creation}

Innovation is key in this design through implementing a plan of free imagery of broken lines to organize spaces, combining rich layers of spatial patterns into a "multiform courtyard", and manifesting abundant spatial pattern. The shape of the Art and Design College demonstrates aspects of this soft "substance". These inner process developments contrast with the Innovation Pioneer Centre design, with its hard straight lines. As the oldest styling 
artwork in human society, "substance" is the coagulation of dual functions of art and design. More than two thousand years ago, Lao Tzu discusses the dialectical relationship between being and nothing. This extends to the issues between form and function. This also indicates the typicality of the carrier of "substance". Therefore, "substance" is the most comprehensive symbol of art and design. We interpret the image and feeling of innovation and inheritance by creating abstract "substance" and deconstructive morphology (Figure 4). Moreover, the straight lines of the Innovation Pioneer Centre of college students is also the symbol of vigorous and innovative college students. A ribbon building connects rigid and soft ones. The architecture and landscape as a whole have been transformed through virtuality and reality, which naturally blended into the imagery of traditional gardens.

\subsection{Deconstruct the Courtyard}

The fashionable courtyard appearance implies the soul of Chinese traditional culture. Different formalized spaces shows the essence of Chinese traditional culture, with characteristics of "polymorphism". There are not only horizontal courtyards but also diagonal and vertical courtyards. Most of them deconstruct the traditional courtyard relationship and form a comfortable, quiet and healthy green campus environment (Figure 4).

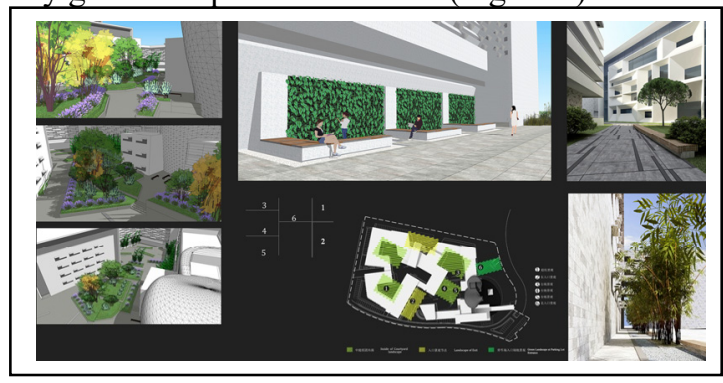

Figure 4. Landscape node explanation

\subsection{Integrated Ecological Landscape}

Landscape design has been integrated into the overall design from the very beginning. This means that, architecture and landscape are self-contained. In the construction of landscape imagery, it has been considered that the courtyard has the potential to go further into abstract forms, which has resulted in putting people into imageries, where one can experience the ever-shifting perspective of mountains beyond mountains. Different from the individual-house-orientated design approach in the west, courtyards in this particular case are mostly a cluster, providing a fractal pattern of Unified Plurality. A hierarchy of the space therefore emerge from a fractal combination. Ultimately, imagery is rooted in "Tao Follows Nature" (Figure 5).

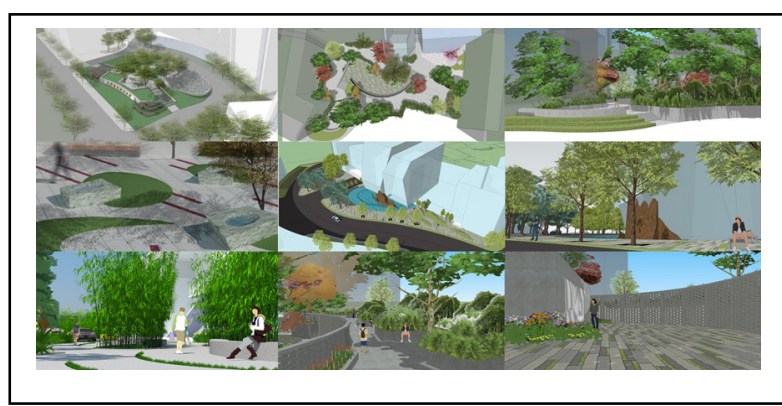

Figure 5. Landscape renderings display

From the perspective of courtyard space in contemporary China, traditional rules of formal beauty, such as balance, unity, rhythm, proportion and scale, have been eliminated in the process of deconstruction, and replaced by open morphological language that disturbs harmonious relations, such as separation, accident, deformation, fragmentation, inclination, superposition, mutation and non-center. This creates a chaotic space with multiple characteristics, such as fragmentation, ambiguity, contingency, ambiguity, game, freedom, openness and promiscuity. Conflicts, confrontations, spaces, fragments and events constitute the topological landscape of the city with multiple hybridization and flowers blooming in full bloom.

\section{Results}

In sum, the western design concept of deconstruction and the Chinese traditional garden concept of construction have been able to reach the same goal. There are similarities and differences in organic non-linear thinking, de-centered thinking, logical structure of text, organization and arrangement of elements, and multiple transformations of scale. As Eisemann points out, deconstruction is actually a very eastern idea. As an innovative design method and aesthetics, deconstruction aims to construct a deep logical structure. This paper analysed the influence of western deconstruction philosophy ideology in design research of Chinese courtyard space. Its purpose was to discuss the inner relation between deconstructive design morphology and the social development, so as to explore new design ideas and methods accorded with the characteristics of the era. Valuable suggestions for design development were able to be forged for future work addressing similar values and constructs.

\section{ACKNOWLEDGMENT}

This research project was supported by Doctoral Research Fund of Jimei University in China (Grant No. Q201715), and Young and Middle-aged Teachers Education Research Fund (Grant No. JAS180179, No.JAS180215). The project of Innovation Pioneer Park of WUT is designed by Prof. Xiduo Yi, and accomplished by his research team together. 


\section{REFERENCES}

1. G. Joseph G. Kronick. Philosophy Beside Itself: On Deconstruction and Modernism (review) [J]. Philosophy and Literature, Volume 11, Number 2, (October 1987), pp. 366-367.

2. G Santayana, George, WG Holzberger, HJJ Saatkamp. The Sense of Beauty: being the outlines of aesthetic theory [M]. Boston: MIT Press, 1988.

3. Peter Eisenman. Post/El Cards: A Reply to Jacques Derrida[J]. Assemblage, No. 12, (Aug., 1990), pp. 14-17.

4. Peter Eisenman. Visions Unfolding $[\mathrm{J}]$. Andreas Papadakis, Geoffrey Broadbent \& Maggie Toy (Editor): Free Spirit in Architecture. New York: St.Martins Press, 1992, pp. 91.

5. Jacques Derrida, Peter Eisenman. Talking About Writing. ANY: Architecture New York [J], Writing in Architecture, (May/June 1993), pp. 18-21.

6. Rem Koolhaas. S, M, L, XL[M]. New York: The Monacelli Press, 1995

7. Lao Tzu. Tao Te Ching[M]. Beijing: Foreign Language Teaching and Research Press, 1998.

8. Ann Whiston Spirn. The Language of Landscape[M]. New Haven: Yale University Press, 2000.

9. Simon Bell. Element of visual design in the landscape[M]. New York: Routledge Press, 2 edition, 2004.

10. Charles Jencks. Critical Modernism: Where is PostModernism Going? What is Post-Modernism?[M]. America: Wiley-Academy Press, 2007.

11. John Patterson. The art of peace: a new reading of the philosophical poem Tao Te Chine/Lao Tzu[M]. Wellington: Steele Roberts Publishers, 2007.

12. Charles Jencks. Critical Modernism: Where is PostModernism Going? What is Post-Modernism?[M]. America: Wiley-Academy Press, 2007.

13. Norman K. Booth. Foundations of landscape architecture: Integrating Form and Space Using the Language of Site Design [M]. New York: Wiley Press, 1 edition, 2011.

14. Nadia Asmoroso. Digital Landscape Architecture Now [M]. London: Thames \& Hudson Press, 1 edition, 2012.

15. Jillian Walliss, Heike Rahmann. Landscape Architecture and Digital Technologies: Reconceptualising design and making [M]. London: Thames \& Hudson Press, 1 edition, 2012.

16. Simon Bell. Landscape: Pattern, Perception and Process, Second Edition[M], London and New York: Routledge Press, 2012.

17. John Dixon Hunt, Forwarded by Peter Walker and Jane Brown Gillette. Site, Sight, Insight: Essays on Landscape Architecture[M], Pennsylvania: University of Pennsylvania Press, 2016. 